\title{
INFLUENCE OF AGE AND HEIGHT POSITION ON COLOMBIAN GUADUA ANGUSTIFOLIA BAMBOO MECHANICAL PROPERTIES
}

\author{
Juan Francisco Correal D. ${ }^{1}$, Juliana Arbeláez, $C .^{2}$
}

\begin{abstract}
The age of bamboo is a key factor that affects its mechanical properties. Bamboo Guadua angustifolia kunt (Guadua a.k.) has been used as a construction material in America, but the influence of the age and height position of the culm on the mechanical properties has not been studied in detail. In this study, selected mechanical properties of Guadua a.k from 2 to 5 year old culms, located at different heights, were investigated using international standard test procedures (ISO 22157). Based on the experimental results, it was found that the top portion (sobrebasa) showed the maximum strength and modulus of elasticity compared to the other portions, since this portion of bamboo has higher density. More over, density of Guadua a.k. culm has more influence in modulus of rupture in bending, than in any of the other studied mechanical properties. Regardless of the culm height, it seems that the mature age of Guadua angustifolia kunt is reached between 3 and 4 years old, because the mechanical properties at those ages were the highest and remained almost constant, whereas the mechanical properties of the culms at the age of 5 were the lowest.
\end{abstract}

Key words: Bamboo, Guadua angustifolia kunt, mature age, mechanical properties.

\section{INTRODUCTION}

Currently, timber is the only sustainable construction material extensively used in the fabrication of structures. Bamboo is an interesting alternative building material to be used since it contributes to the oxygenation of the environment and captures carbon dioxide. Besides, bamboo has high strength to weight ratio, relative low cost, and fast growing rate. Therefore, it is important to have the mechanical and physical characterization of all bamboo species, in order to have a more reliable understanding of their behavior for a better structural design and performance. Researchers around the world (Abd. Latif. et al. 1990, Norul et al. 2006, Sattar et al. 1990) have found that the age of bamboo is considered to be a key factor that influences its mechanical properties. Liese and Weiner (1996) reviewed the relationship between bamboo ageing and maturation. They reported that bamboo culms mature at about two to three years old reaching its maximum strength.

A giant species of bamboo called Guadua angustifolia kunt (Guadua a.k.) grows naturally in Colombia, and people have used it as a structural raw material, based on the experience passed from generation to generation. Moreover, Guadua a.k. is probably the most popular species of bamboo used as a construction material in countries like Ecuador, Peru, Costa Rica and Mexico. Pavilion Zeri in Manizales Colombia (by Simón Veléz), the Multi-Purpose Hall "Amantes de Sumpa” in Santa Elena's province in Ecuador (by Daniela Loisa and Jorge Moran), "Isla en el Desierto" in State of Piura (by Eliseo Guzmán) in Peru, Bamboo Housing National Project (by Fundación del Bambú (FUNBAMBU)) in Costa Rica, Ecological cabins and "Flor del Bosque" classroom (by Ricardo Leyva) in Puebla Mexico, are some of the many examples of structures made of Guadua a.k. Towards a better processing and utilization of Guadua a $k$ as a construction material, it is imperative to have a systematic characterization of its mechanical properties. Additionally, in order to establish the age of the culms, it is necessary to replace traditional methods used to determine the age (visually-aged) by a more systematic method like marking the new shoots and monitoring their age. Only one preliminary study (Gritsch et al. 2004)

\footnotetext{
'Director del Laboratorio Integrado y Profesor Asistente del Departamento de Ingeniería Civil y Ambiental, Universidad de los Andes, Bogotá, Colombia, jcorreal@uniandes.edu.co

${ }^{2}$ Asistente graduado, Departamento de Ingeniería Civil y Ambiental, Universidad de los Andes, Bogotá, Colombia, juli-arb@uniandes.edu.co

Corresponding author: jcorreal@uniandes.edu.co

Received: 18.02.2010.Accepted: 18.06. 2010
} 
has been done on the relationship between the age of Guadua a.k. culms and the compressive strength parallel to grain. The authors did not find a relationship between age and compressive strength.

A comprehensive study on round Guadua a.k. as a structural material is conducted at Universidad de los Andes in Bogotá, Colombia. As a part of this study and for the first time, shear and compression parallel to grain, and static bending tests were performed on 2, 3,4 and 5 year old Guadua a.k. culm samples located at three height positions along the culm (bottom, middle and top). The aim of this work was to find the most suitable age of Guadua angustifolia kunt to ensure its maximum strength for a better use in the construction industry.

\section{MATERIAL AND METHODS}

Two, three, four and five year old culms of Guadua a.k. from the city of Caicedonia in Colombia, located at 1400 meters above the sea level, were used in this study. The average height of the culms varied between 20 to 30 meters. The culm age was determined by a mark on the new shoots that shows the semester and year when they emerged from the ground. Felling, identification and dispatching (according to ISO 22157 (2004)) of culms were carried out by Colguadua Ltda. Five meters long culm portions were taken at three different heights called Cepa (bottom), Basa (middle) and Sobrebasa (top) as shown in Figure 1. The average diameters for the bottom, middle and top culms were $13 \mathrm{~cm}, 12 \mathrm{~cm}, 10 \mathrm{~cm}$, respectively. Guadua a.k. culms were dispatched within two weeks after felling to the structural laboratory at the Universidad de los Andes in Bogotá- Colombia, in order to have green culms with moisture content (MS) above the fiber saturation point (MS over 30\%). Culms were tested in a green condition, in order to allow a direct comparison between mechanical properties at different ages and height. Guadua a.k. mechanical properties are not expected to vary with MS when it is over $30 \%$, and the wet service factor (factor that take into account the influence of MS in the mechanical properties) is not need to be considered.

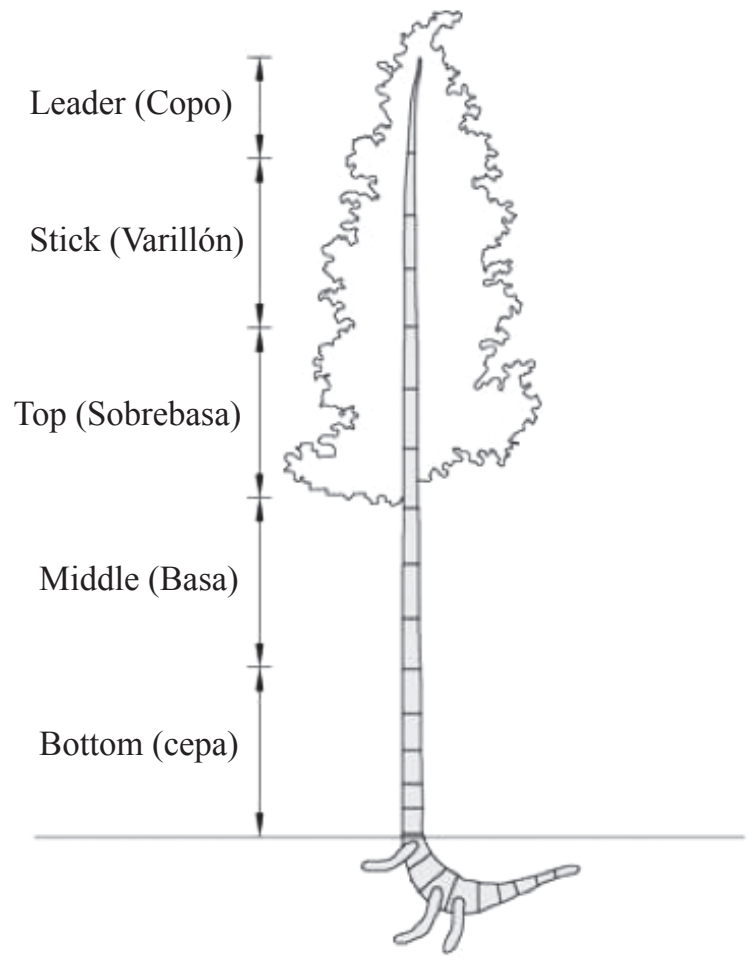

Figure 1. General parts of Guadua a.k. 
Compression and shear parallel to grain, and bending tests were performed in this research. Mechanical properties from those tests were determined following the specifications given by the Instituto Colombiano de Normas Técnicas y Certificación (NTC 5525-2007), which are based on the ISO standards 22157 (2004). For each mechanical property, ten samples of each age and portion of Guadua a.k. culms were tested. Temperature, moisture content and relative humidity were recorded for all specimens. The compression and shear tests were conducted on a MTS Universal Testing Machine having a self-aligning seat with a continuous motion of the movable head (Figures 2 and 3 ). The compression test was performed using Teflon-coated steel plates with a combination of wedges (Figure 2) in order to reduce friction at the contact points and decrease radial stresses in the test sample. Friction at the contact points imposes a lateral restriction to the sample during the test, resulting in an apparent higher strength. Based on ISO 22157, steel circular plates with specific geometry were designed in order to generate four shear planes as shown in Figure 3. A MTS hydraulic actuator supported in a steel load frame was used for the four point bending test as presented in Figure 4. The load was applied through a series of straps located at the Guadua a.k. nodes and attached to an adjustable steel saddle that allows rotation at the load points as well as at the supports. The data necessary to calculate compressive, shear and bending strength (MOR) and modulus of elasticity in compression and bending (MOE) was recorded in digital format.

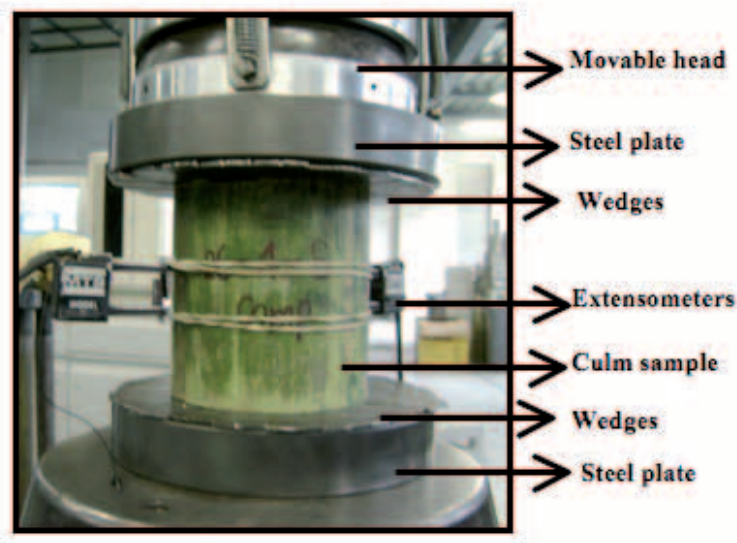

a) Test Setup

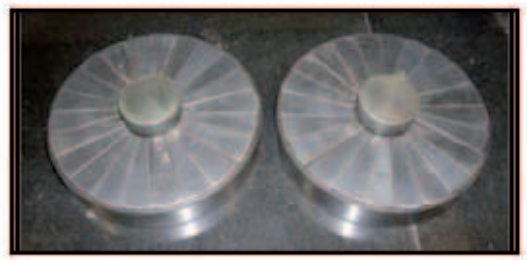

b) Steel plate with wedges

Figure 2. Compressive test setup and steel plates

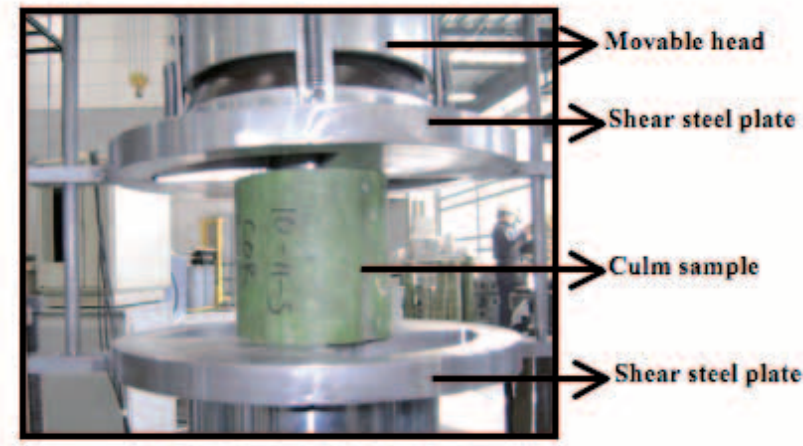

a) Test Setup

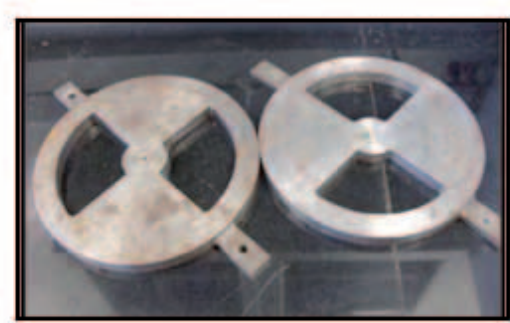

b) Shear steel plate

Figure 3. Shear test setup and steel plates 


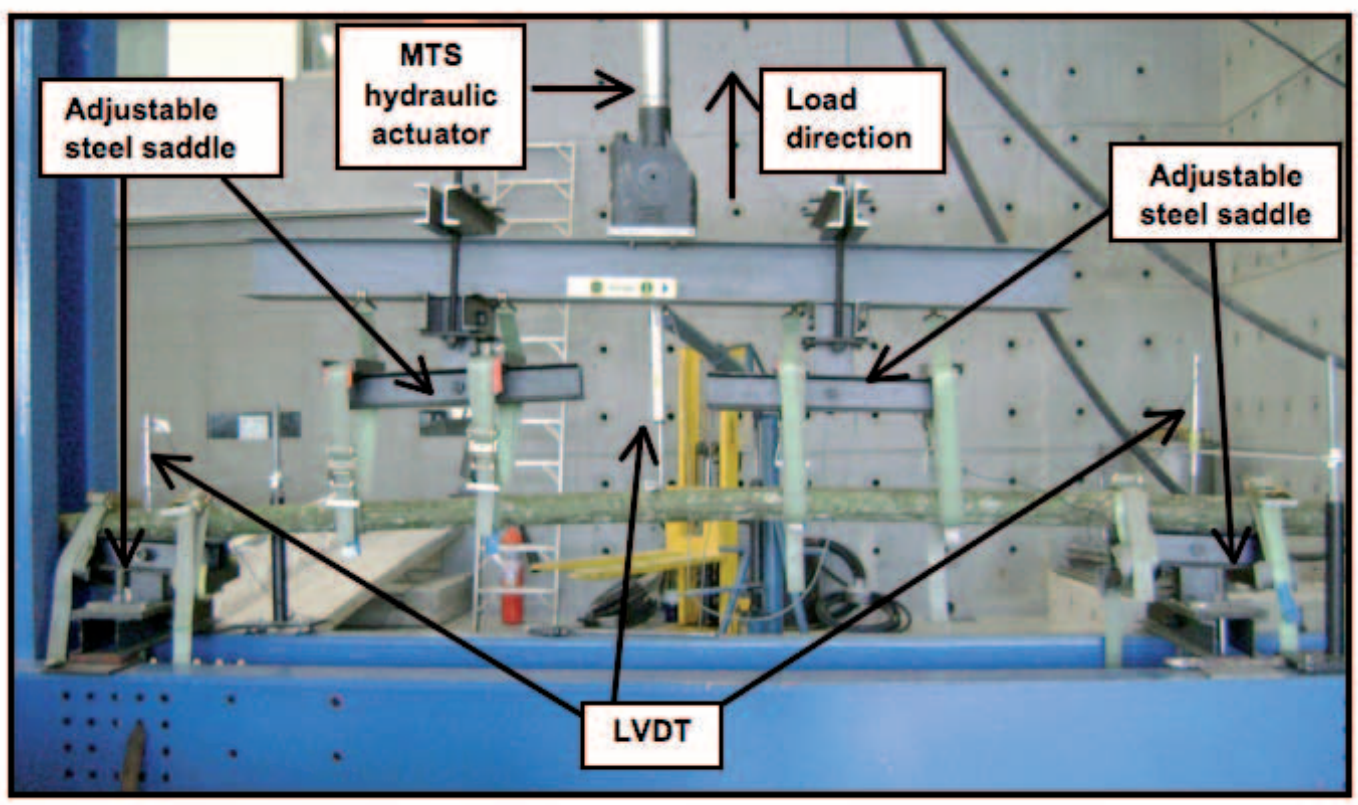

Figure 4. Bending test setup

\section{RESULTS AND DISCUSSION}

An average relative humidity of $68 \%$ and an average temperature of $13.3^{\circ} \mathrm{C}$ were recorded in the lab for all the samples tested. The average values of moisture content for 2, 3, 4 and 5 year old culms were $59.3 \%, 56.5 \%, 56.7 \%$ and $65.2 \%$, respectively. The moisture contents confirmed that all culms were in a green condition, since they were over $30 \%$. As a result, the effect of moisture content in the mechanical properties did not need to be taken into account.

Table 1 presents the average values of density and the mechanical properties obtained for the compression, shear and bending tests at different culm heights and ages. Average values of density and the mechanical properties regardless the ages as wells as the average properties regardless the height position are also shown in Table 1 (bold text). Based on values of Table 1, the top portion of the Guadua a.k. culm (sobrebasa) showed the maximum values compared to the other two portions, for all the mechanical properties. The same behavior has been observed in other bamboo species as reported by Kamruzzaman et al. (2008) and Sattar et al. (1990). Except for MOR, the mechanical properties of the top portion of the Guadua a.k. (sobrebasa) were about $10 \%$ higher compared to the lower portion (cepa). MOR at the top portion of the guadua culm was 17\% higher than that of the lower portion. Liese and Weiner (1996) stated that density increases along the culm length and therefore, mechanical properties increase with height. They explain that the change of density along the height of bamboo is due to the fact that wall thickness decreases from bottom to top of the culm with no reduction of the amount of fibers in the cross section of the culm. Thus, the top portion of the bamboo culms exhibits higher volume ratio of fibers to parénquima. Nonetheless and taking into account the results from the current study, not all the mechanical properties are affected in the same way. Particularly for MOR, it seems that beyond the elastic range, most of the tensile stress is taken by the fibers, while in compression and mainly in shear tests; stresses are taken by the parenchyma with a smaller contribution from the fibers. The effect on culm height position in mechanical properties will be discussed afterwards based on statistical analysis. 
Table 1. Average values of density and mechanical properties of Guadua angustifolia by height position and age

\begin{tabular}{|c|c|c|c|c|c|c|c|}
\hline & & Age (ye & r) & 3 & 4 & 5 & $\begin{array}{c}\text { By height } \\
\text { position }\end{array}$ \\
\hline & Bottom & $\rho$ & 674.5 & 681.9 & 617.3 & 676.9 & 663.3 \\
\hline Density & Middle & $\rho$ & 678.1 & 705.5 & 780.0 & 780.0 & 696.3 \\
\hline & Top & $\rho$ & 703.0 & 828.6 & 774.1 & 735.4 & 764.6 \\
\hline & By age & $\rho$ & 687.3 & 748.0 & 725.9 & 686.1 & \\
\hline & & $\mathbf{E}$ & 15.5 & 16.5 & 17.4 & 15.2 & 16.3 \\
\hline & & $\boldsymbol{\sigma}$ & 39.9 & 38.1 & 37.6 & 32.1 & 36.8 \\
\hline & Middlo & $\mathbf{E}$ & 14.9 & 18.0 & 16.8 & 16.5 & 16.8 \\
\hline Compression & 1910 & $\boldsymbol{\sigma}$ & 27.2 & 42.1 & 41.5 & 34.7 & 36.6 \\
\hline & Ton & $\mathbf{E}$ & 20.0 & 17.0 & 17.5 & 18.2 & 17.9 \\
\hline & $10 \mathrm{p}$ & $\boldsymbol{\sigma}$ & 20.4 & 42.6 & 42.1 & 39.0 & 36.8 \\
\hline & Denos & $\boldsymbol{\sigma}$ & 28.6 & 41.0 & 40.4 & 35.2 & \\
\hline & By age & $\mathbf{E}$ & 16.4 & 17.2 & 17.2 & 16.8 & \\
\hline & Bottom & $\tau$ & 7.2 & 7.4 & 7.5 & 6.6 & 7.1 \\
\hline & Middle & $\tau$ & 7.5 & 8.2 & 8.0 & 7.4 & 7.8 \\
\hline Shear & Top & $\tau$ & 7.2 & 8.1 & 7.6 & 8.0 & 7.8 \\
\hline & By age & $\tau$ & 7.3 & 7.9 & 7.7 & 7.3 & \\
\hline & Rottom & MOE & 16.9 & 16.7 & 17.0 & 18.0 & 17.2 \\
\hline & Dotion & MOR & 93.6 & 88.8 & 86.9 & 86.3 & 88.6 \\
\hline & Middlo & MOE & 17.7 & 15.8 & 17.0 & 18.7 & 17.2 \\
\hline Rending & Midade & MOR & 84.7 & 91.6 & 103.7 & 86.9 & 91.9 \\
\hline Denuing & Ton & MOE & 16.1 & 19.4 & 18.3 & 15.5 & 17.2 \\
\hline & $10 \mathrm{p}$ & MOR & 107.3 & 97.8 & 103.8 & 107.0 & 104.1 \\
\hline & Ry age & MOR & 95.8 & 92.7 & 98.5 & 93.4 & \\
\hline & & MOE & 16.9 & 17.1 & 17.4 & 17.4 & \\
\hline
\end{tabular}

Note: $\rho=$ Density $\left(\mathrm{kg} / \mathrm{m}^{3}\right), \mathrm{E}=$ modulus of elasticity $(\mathrm{GPa}), \sigma=$ compressive strength (MPa), $\tau=$ shear strength $(\mathrm{MPa}), \mathrm{MOE}=$ modulus of elasticity $(\mathrm{GPa}), \mathrm{MOR}=$ modulus of rupture $(\mathrm{MPa})$

In order to establish a comparison between Guadua a.k. and other species of bamboo (in green conditions), the relationship between different culm ages and average values of the compressive and shear strength, and modulus of rupture in bending (MOR) are presented in Figures 5 to 7, respectively. Based on Figure 5 and for Guadua a.k., the maximum compressive strength was observed in 3 year old culms. Nonetheless, the difference between compressive strength for 3 and 4 years old culms is only $1 \%$. In contrast, the compressive strength at 5 years old decreased about $16 \%$ compared to the strength for 3 and 4 years old. Bambusa balcooa and Melocanna baccifera present the same behavior in compression as Guadua a.k. with the three species having similar strength, peak strength between 3 to 4 years old, and decreasing strength at the age of 5 years. Compressive strength of Gigantochloa scortechinii, Bambusa vulgaris, and Bambusa blumeana was 25\% and 27\% lower than compressive strength values of Guadua a.k. for 2 and 3 year old culms, respectively. 


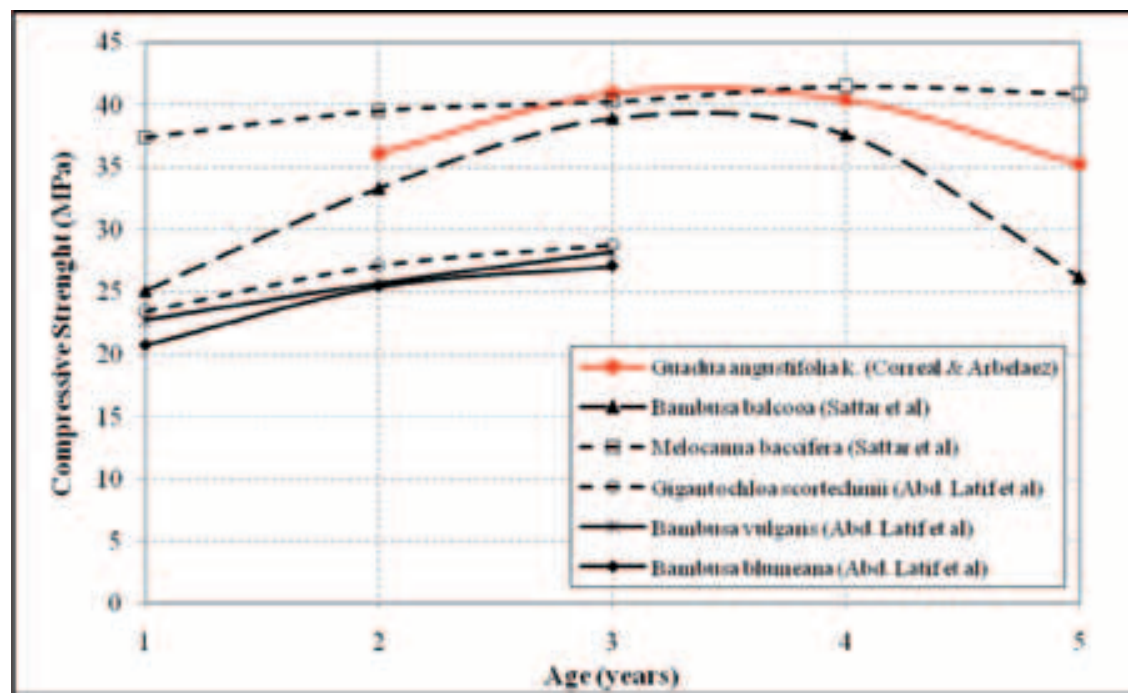

Figure 5. Variation of compressive strength for different bamboo species with age

In the same manner as the compressive strength, the maximum shear strength was reached for 3 year old Guadua culms (Figure 6). Additionally, shear strength decreased at the age of 4 and 5 years with a difference of $3 \%$ and $10 \%$, compared to 3 year old culms, respectively. Guadua a.k presents higher shear strength compared to Gigantochloa scortechinii, Bambusa vulgaris, and Bambusa blumeana, with a difference between Guadua $a . k$ and those species of 38\% and 39\% for 2 and 3 year old culms, respectively.

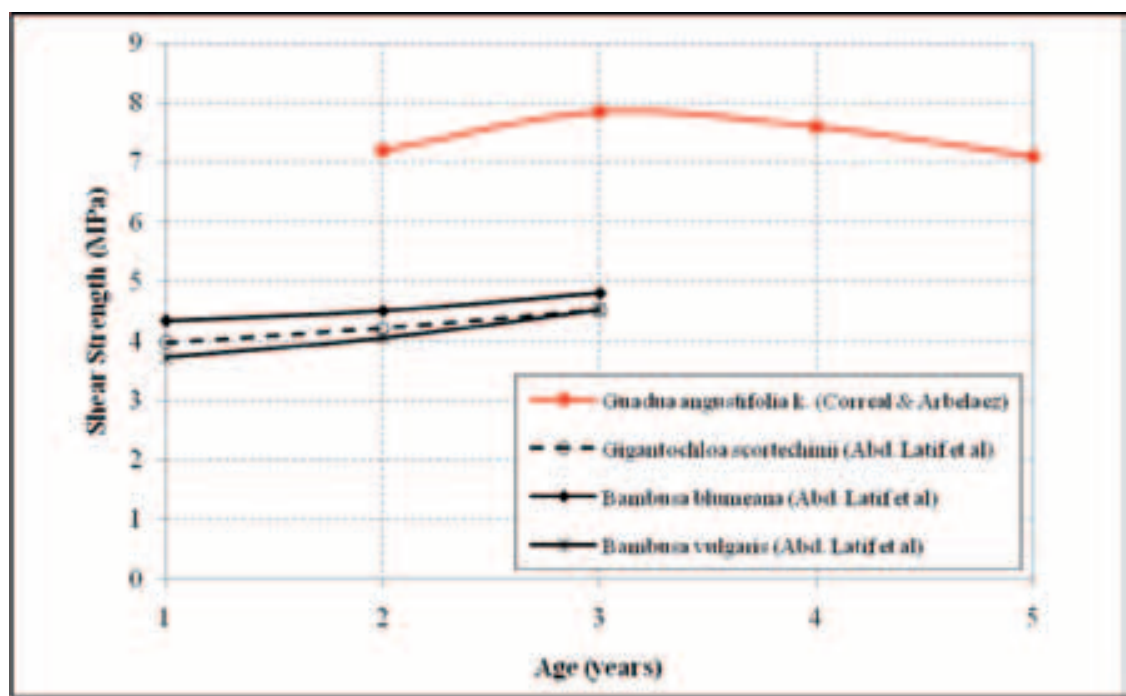

Figure 6. Variation of shear strength for different bamboo species with age

Figure 7 presents the average values of MOR at different ages for some bamboo species. MOR of Guadua a.k. presents the same behavior found for compressive and shear strength, with a maximum average value of MOR for 3 year old culms, and decreasing values for 4 and 5 year old 
culms. The difference between MOR for 3 years old and MOR at 4 and 5 years old was $2 \%$ and 11\%, respectively. Like Guadua a.k., Bambusa balcooa (Sattar. et al 1990) and Melocanna baccifera (Sattar. et al 1990) present the maximum value of MOR at 3 years old with lower values at 4 and 5 year old culms. MOR in Guadua a.k. is about the same than that of Bambusa blumeana at 2 and 3 year old culms. However, Guadua a.k. shows higher MOR than Bambusa balcooa, Meloccana baccifera, Gigantochloa scortechinii and Bambusa vulgaris at all ages. Particularly for 3 year old culms, MOR in Guadua a.k. was $20 \%$ to $39 \%$ higher than MOR of Bambusa balcooa, Meloccana baccifera, Gigantochloa scortechinii and Bambusa vulgaris.

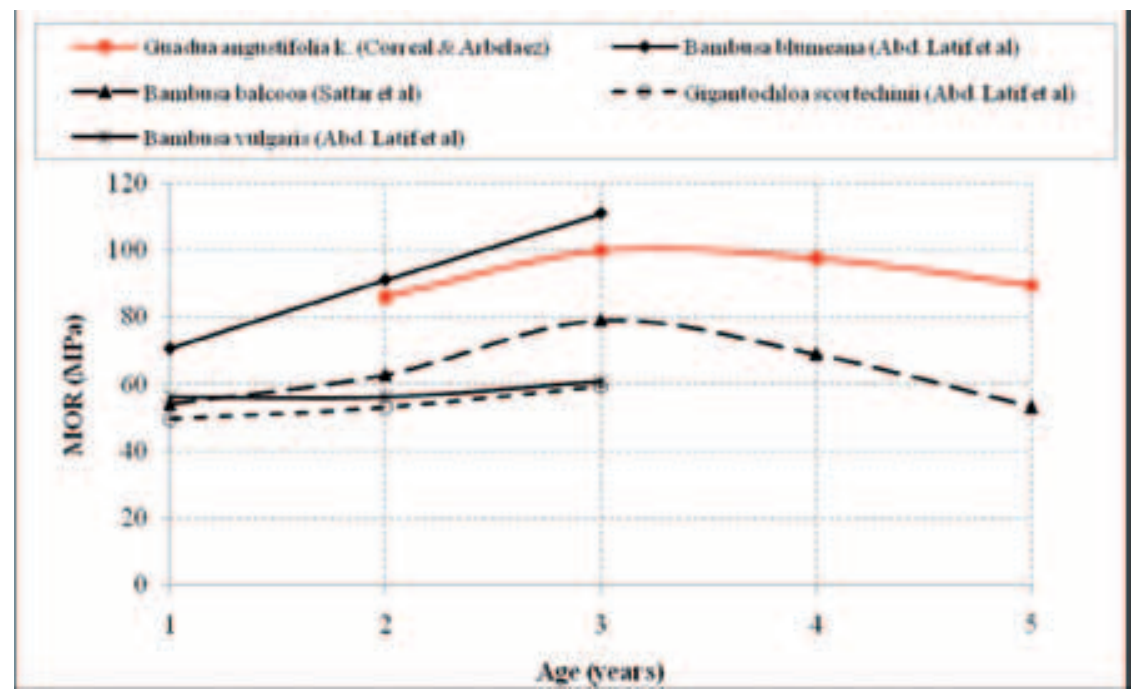

Figure 7. Variation of modulus of rupture (MOR) of different bamboos species with age

In general, most of the mechanical properties of Guadua a.k. exhibited higher values of strength for 3 and 4 year old culms. Thus, it seems that the mature age of Guadua a.k. culms is reached between 3 to 4 years. Furthermore, the strength for 5 year old culms decreases when compared to 3 and 4 year old culms. This behavior could be related to the decreasing of density at 5 years old due to possible changes or modifications in the anatomical structure with ageing and dying fibers in bamboo (Liese and Weiner 1996), which needs to be verified by more detailed studies.

Results of the analysis of variance (ANOVA) performed for the data of density and mechanical properties in relation to culm height position and age are shown in Table 2. ANOVA results show that density, compressive strength and MOR are directly affected by the culm height position and age. As it was mentioned before, variation in fiber volume to parenquima ratio along the height of bamboo (Liese and Weiner 1996) and ageing of fibers (Liese and Weiner 1996) affect density and some mechanical properties like compressive strength and MOR since those properties are dependent on the amount and quality of the fibers in the bamboo culms. In contrast, variation of properties like shear strength, modulus of elasticity in compression and MOE with culm age are not statistically significant. Therefore, it appears that the behavior of an element subjected to compression or bending (columns or beams) in the elastic range will not be affected by the age of the Guadua a.k. culms if those are between 3 and 5 years old. 
Table 2. Summary of variance analysis for density and mechanical properties of Guadua angustifolia kunt

\begin{tabular}{|c|c|c|c|}
\hline \multirow{2}{*}{\multicolumn{2}{|c|}{ Property }} & \multicolumn{2}{|c|}{ Computed F-Value } \\
\hline & & Height position & Age \\
\hline \multirow{2}{*}{\multicolumn{2}{|c|}{ Density }} & $10.08^{* *}$ & $6.84^{* *}$ \\
\hline & & $(3.26 ; 5.25)$ & $(3.26 ; 5.25)$ \\
\hline \multirow{4}{*}{ Compression } & \multirow{2}{*}{$\sigma$} & $3.73^{*}$ & $4.98^{* *}$ \\
\hline & & $(3.11 ; 4.87)$ & $(2.71 ; 4.02)$ \\
\hline & \multirow{2}{*}{ E } & $11.91^{* *}$ & $0.97^{\mathrm{NS}}$ \\
\hline & & $(3.11 ; 4.87)$ & $(2.71 ; 4.02)$ \\
\hline \multirow{2}{*}{ Shear } & \multirow{2}{*}{$\tau$} & $0.66^{\mathrm{NS}}$ & $1.44^{\mathrm{NS}}$ \\
\hline & & $(3.11 ; 4.87)$ & $(2.71 ; 4.02)$ \\
\hline \multirow{4}{*}{ Bending } & \multirow{2}{*}{ MOR } & $22.06^{* *}$ & $3.88^{*}$ \\
\hline & & $(3.11 ; 4.87)$ & $(2.71 ; 4.02)$ \\
\hline & \multirow{2}{*}{ MOE } & $1.66^{\mathrm{NS}}$ & $1.66^{\mathrm{NS}}$ \\
\hline & & $(3.11 ; 4.87)$ & $(3.11 ; 4.87)$ \\
\hline \multicolumn{4}{|c|}{$\begin{array}{l}\sigma=\text { compressive strength, } \mathrm{E}=\text { modulus of elasticity, } \tau=\text { shear strength, } \\
\mathrm{MOE}=\text { modulus of elasticity, } \mathrm{MOR}=\text { modulus of rupture }\end{array}$} \\
\hline \multicolumn{4}{|c|}{$\begin{array}{l}\text { Numbers in parentheses are critical F-values at } \alpha=0.05 \text { and } \alpha=0.01 \text {, respectively } \\
\text { *significant: }{ }^{* *} \text { highly significant: }{ }^{N S} \text { not significant }\end{array}$} \\
\hline
\end{tabular}

\section{CONCLUSIONS}

Based on the results of mechanical properties (compression, shear and bending) obtained in this research, the following conclusions are drawn for round Guadua angustifolia kunt for ages between 2 to 5 years:

For all the mechanical properties studied and regardless of the age of culms, the top portion (sobrebasa) shows the maximum strength and modulus of elasticity compared to the lower two portions. This behavior is mainly due to the higher density at the top portion of bamboo, having more influence on compressive strength and MOR than for other mechanical properties.

Modulus of elasticity in compression and MOE are not affected by either culm height position or culm age. Thus, the behavior of a structural element subjected to compression or bending forces in the elastic range will not be affected by the age of the culm if it ranges between 3 to 5 years old.

Regardless of the locations of culms, it seems that the mature age of Guadua a.k. is reached between 3 and 4 years old since mechanical properties at those ages were the highest and remain almost constant. In addition, it was found that the maximum values for density were found for 3 and 4 year old culms.

Compressive, shear and bending strength at 5 year old culms decrease compared to 3 and 4 year old culms. Decreasing of density at 5 year old culms compared to 2 and 3 year old culms was found. The change of the anatomical structure of Guadua a.k. in relation to ageing and dying fibers needs to be investigated in detail. 


\section{ACKNOWLEDGEMENT}

The research presented in this paper is sponsored by the Ministry of Agriculture and Rural Development of Colombia (Contract No 030-2007M3307-920-07), Universidad de los Andes and Colguadua Ltda. Thanks to Dr. Fernando Ramirez, Luis F. Lopez, and the staff of the Center of Research in Materials and Civil Works (CIMOC), and the Structural Lab Models at the Universidad de Los Andes in BogotáColombia for their help and support.

\section{REFERENCES}

Abd Latif, M.; Wan Tarmeze, W. A.; Fauzidah, A. 1990. Anatomical features and mechanical properties of three malasyan bamboos. Journal of Tropical Forest Science 2 (3): 227-234.

Gritsch, C. S.; Abranson, K.; Camayo Velez, G.C.; Rashid, M.; Murphy, R. J.; Camargo, J. C.; Londoño, J. 2004. Anatomical culm analysis of Guadua angustifolia in relation to age, site and physico-mechanical properties. In proceedings of International Symposium of Guadua. 2004. Pereira, Colombia.

International Standard Test Procedures. 2004. ISO Standard 22157, Determination of physical and mechanical properties of bamboo, International Organization for Standardization (ISO).

Norma Técnica Colombiana. 2007. NTC 5525, Determinación de las propiedades físicas y mecánicas de la Guadua Angustifolia Kunth, Instituto Colombiano de Normas Técnicas (ICONTEC).

Liese, W.; Weiner, G. 1996. Ageing of bamboo culms. A review. Wood Science and Technology 30: 77-89.

Norul H, H.; Othman, S.; Rokiah, H.; Abd. L, M.; Ani, S.; Mohod T, M. 2006. Caracterization of bamboo Gigantochloa Scortechinii at different ages. Journal of Tropical Forest Science 18 (4): 236-242.

Sattar, M. A.; Kabir, M. F.; Bhattacharjee, D. K. 1990. Effect of age and height position of muli (Melocanna Baccifera) and borak (Bambusa Balcooa) bamboos on their physical and mechanical properties. Bangladesh Journal of Forest Science 19: 29-37. 
